\title{
Efektivitas Terapi Intervensi Non Farmakologis pada Persalinan Parturien Pervaginam
}

\author{
Ravenska Salawati, ${ }^{1}$ Barry Kambey, ${ }^{2}$ Harold Tambajong ${ }^{2}$
}

\author{
${ }^{1}$ Program Studi Pendidikan Dokter Fakultas Kedokteran Universitas Sam Ratulangi, Manado, \\ Indonesia \\ ${ }^{2}$ Bagian Anestesiologi dan Terapi Intensif Fakultas Kedokteran Universitas Sam Ratulangi, \\ Manado, Indonesia \\ Email: ravenskaelika@gmail.com
}

\begin{abstract}
Pain during labor is common. Albeit, if it is untreated, it could have a negative impact on the mother and fetus. Non-pharmacological managements such as acupressure and transcutaneous electrical nerve stimulation (TENS) are expected to reduce vaginal delivery pain. This study was aimed to determine the effect of acupressure and TENS on the intensity of delivery pain. This was a literature review study using three databases, namely clinical key, pubmed, and google scholars. The keywords used were non Pharmacology, childbirth, pain labor, pain management, non-pharmacology. Based on inclusion and exclusion criteria, 10 literatures were selected. The results showed significant changes in pain intensity after giving acupressure therapy and TENS in mothers who were in the first phase of the labor active phase. In conclusion, acupressure and TENS could reduce the intensity of vaginal delivery pain.
\end{abstract}

Keywords: vaginal delivery, acupressure, transcutaneous electrical nerve stimulation (TENS)

\begin{abstract}
Abstrak: Nyeri pada persalinan merupakan hal yang lumrah terjadi namun jika tidak ditangani dapat berdampak buruk bagi kesehatan ibu dan janin. Manajemen non-farmakologis akupresur dan transcutaneous electrical nerve stimulation (TENS) diharapkan dapat mengurangi nyeri persalinan pervaginam. Penelitian ini bertujuan untuk mengetahui pengaruh akupresur dan TENS terhadap intensitas nyeri persalinan. Jenis penelitian ialah literature review. Pencarian data menggunakan tiga database yaitu ClinicalKey, Pubmed, dan Google Scholar. Kata kunci yang digunakan yaitu Non Farmakologi", "Persalinan", "Pain Labor", "Pain management", "Non Pharmacology". Setelah diseleksi berdasarkan kriteria inklusi dan ekslusi didapatkan 10 literatur. Hasil penelitian ini mendapatkan perubahan bermakna setelah pemberian terapi akupresur maupun TENS pada ibu bersalin kala I fase aktif. Simpulan penelitian ini ialah penggunaan akupresur dan TENS berpengaruh dalam menurunkan intensitas nyeri persalinan pervaginam.

Kata kunci: persalinan pervaginam, akupresur, transcutaneous electrical nerve stimulation (TENS)
\end{abstract}

\section{PENDAHULUAN}

Nyeri merupakan sensasi tidak menyenangkan, yang terjadi dalam berbagai tingkat keparahan sebagai konsekuensi dari cedera, penyakit, atau gangguan emosional. ${ }^{1}$ The International Association for the Study of Pain mendefinisikan nyeri sebagai "Pengalaman sensoris dan emosional yang tidak menyenangkan yang terkait dengan kerusakan jaringan aktual atau poten-sial, atau yang dapat dirasakan dalam suatu kejadian." Dalam kasus tertentu, nyeri mungkin dialami tanpa adanya cedera jaringan yang jelas namun rasa sakitnya tidak kalah "nyata". 2 Informasi baru menekankan betapa pentingnya memandang pengalaman nyeri sebagai pengalaman neurobiologis kompleks yang dipengaruhi 
oleh berbagai faktor yang terjadi di berbagai area sistem saraf perifer dan pusat. ${ }^{2}$

Nyeri pada persalinan dipengaruhi oleh kontraksi rahim yang menyebabkan dilatasi serta penipisan serviks dan iskemia rahim yaitu penurunan aliran darah sehingga oksigen lokal mengalami defisit akibat kontraksi miometrium. Rasa takut, cemas, dan tegang yang berlebihan pada wanita hamil merupakan faktor psikologis yang dianggap juga berpengaruh dalam terjadinya rasa nyeri pada saat proses persalinan. ${ }^{3,4}$ Nyeri yang tidak ditangani saat melahirkan dapat berdampak buruk bagi kesehatan ibu dan janin. Peningkatan aktivitas sistem saraf simpatis menyebabkan lonjakan katekolamin. Hiperventilasi, dan peningkatan laju metabolisme yang mengakibatkan konsumsi oksigen yang lebih besar dan dapat menyebabkan hipokarbia dan hipoksemia. ${ }^{5}$ Murray melaporkan kejadian nyeri pada $2.700 \mathrm{ibu}$ bersalin, $20 \%$ persalinan disertai nyeri sangat hebat $15 \%$ mengalami nyeri ringan, $35 \%$ dengan nyeri sedang, $30 \%$ dengan nyeri hebat. ${ }^{6-8}$

Akupresur merupakan salah satu pengobatan tradisional dengan teknik menekan, memijat, serta mengurut bagian tubuh untuk mengaktifkan peredaran energi. Li4, dan SP6 ialah titik yang digunakan dalam terapi akupresur dalam mengelola nyeri persalinan. ${ }^{9}$ Transcutaneous electrical nerve stimulation (TENS) merupakan salah satu pilihan analgesia non-farmakologi yang dapat mengurangi nyeri saat persalinan melalui elektroda yang dipasang sejajar T10 (torakal 10) dan L1 (lumbal 1) pada punggung ibu dan dua elektroda lainnya dipasang di antara S2 dan S4 (sakral 2 dan 4). ${ }^{10}$

\section{METODE PENELITIAN}

Penelitian ini merupakan suatu literature review. Pencarian literatur menggunakan database elektronik yaitu Pubmed, ClinicalKey dan Google Scholar. Kata kunci yang digunakan dalam bahasa Indonesia dan bahasa Inggris ialah "Manajemen Nyeri", "Non Farmakologi", "Persalinan", dan "Non Farmakologi", "Farmakologi", "Pain Labor", "Pain management", "Non Pharmacology", dan "Pharmacology".

\section{HASIL PENELITIAN}

Pada pencarian literatur sesuai kata kunci dan berdasarkan tahun, didapatkan Pubmed 4.217 literatur, Clinicalkey 197 literatur, dan Google scholar 3.450 literatur. Setelah disesuaikan dengan kriteria inklusi maka jumlah literatur yang tersisa sebanyak 10 literatur untuk dikaji.

Penelitian yang dipakai sebagian besar berasal dari beberapa daerah di Indonesia, namun terdapat satu penelitian yang berasal dari Arab Saudi. Tabel 1 memperlihatkan karakteristik masing-masing literatur yang dikaji dalam penelitian ini.

Tabel 2 memperlihatkan hasil uji statistik masing-masing literatur penelitian. Uji statistik yang dipakai bervariasi, yaitu $T$-test dependent, Mann-Whitney, Wilcoxon, dan chi-square dengan nilai $\mathrm{p}$ masing-masing.

Tabel 1. Perbandingan karakteristik masing-masing literatur

\begin{tabular}{|c|c|c|c|c|c|}
\hline No & Peneliti & Judul & Sampel & Metode & Hasil \\
\hline 1 & $\begin{array}{l}\text { Vitriani } \\
\text { et al, } \\
2017 .{ }^{11}\end{array}$ & $\begin{array}{l}\text { Pengaruh terapi } \\
\text { akupresur terha- } \\
\text { dap intensitas nye- } \\
\text { ri pada ibu bersa- } \\
\text { lin kala I di } \\
\text { Puskesmas } \\
\text { Sedinginan tahun } \\
2017\end{array}$ & 15 & $\begin{array}{l}\text { Pre- } \\
\text { eksperi- } \\
\text { mental }\end{array}$ & $\begin{array}{l}\text { Rerata (mean) intensitas nyeri persalinan pada } \\
\text { ibu bersalin kala I fase aktif sebelum dilakukan } \\
\text { terapi akupresur ialah } 7.80 \text { dengan standar } \\
\text { deviasi } 0,862 \text {. }\end{array}$ \\
\hline 2 & $\begin{array}{l}\text { Dewiani } \\
\text { et al, } \\
2014 .^{12}\end{array}$ & $\begin{array}{l}\text { Terapi akupresur } \\
\text { terhadap pengu- } \\
\text { rangan nyeri dan } \\
\text { lama persalinan }\end{array}$ & 30 & $\begin{array}{l}\text { Semi- } \\
\text { eksperi- } \\
\text { mental }\end{array}$ & $\begin{array}{l}\text { Nyeri persalinan yang mendapatkan akupresur } \\
\text { yang mempunyai nyeri ringan sebesar } 40 \% \\
\text { sedangkan yang tidak mendapatkan akupresur } \\
\text { mempunyai nyeri ringan sebesar } 10 \%\end{array}$ \\
\hline
\end{tabular}




\begin{tabular}{|c|c|c|c|c|c|}
\hline & & $\begin{array}{l}\text { kala I pada primi- } \\
\text { gravida }\end{array}$ & & & \\
\hline 3 & $\begin{array}{l}\text { Sulistyo- } \\
\text { ningrum, } \\
2017 . .^{13}\end{array}$ & $\begin{array}{l}\text { Pengaruh teknik } \\
\text { akupresur terha- } \\
\text { dap pengurangan } \\
\text { intensitas nyeri } \\
\text { kala I persalinan }\end{array}$ & 31 & $\begin{array}{l}\text { Semi- } \\
\text { eksperi- } \\
\text { mental }\end{array}$ & $\begin{array}{l}\text { Intensitas nyeri responden sebelum dilakukan } \\
\text { akupresur rata-rata mencapai } 6,03 \text { dengan } \\
\text { standar deviasi } 1,602 \text { dan setelah dilakukan } \\
\text { akupresur rerata tingkat nyeri ibu inpartu } 3,24 \\
\text { dengan standar deviasi } 1,403 \text {. }\end{array}$ \\
\hline 4 & $\begin{array}{l}\text { Puspa- } \\
\text { dewi, } \\
\text { Lokawati } \\
2014 .^{14}\end{array}$ & $\begin{array}{l}\text { Pengaruh akupre- } \\
\text { sur dalam mengu- } \\
\text { rangi nyeri persa- } \\
\text { linan kala I fase } \\
\text { aktif pada primi- } \\
\text { gavida di BPM } \\
\text { Ngidila } \\
\text { Kecamatan Pakis - } \\
\text { Malang }\end{array}$ & 15 & $\begin{array}{l}\text { Pre- } \\
\text { eksperi- } \\
\text { mental }\end{array}$ & $\begin{array}{l}\text { Sebanyak } 80 \% \text { responden mengalami nyeri } \\
\text { berat dan } 13,3 \% \text { mengalami nyeri sangat berat. } \\
\text { Setelah diberikan akupresure pada } 15 \text { responden } \\
\text { dapat disimpulkan bahwa } 4 \text { responden }(26,6 \%) \\
\text { mengalami nyeri sedang, } 12 \text { responden }(73,3 \%) \\
\text { mengalami nyeri berat, dan tidak ada responden } \\
\text { yang mengalami nyeri sangat berat. }\end{array}$ \\
\hline 5 & $\begin{array}{l}\text { Nanur, } \\
\text { Masru- } \\
\text { roh, } \\
2013 .{ }^{15}\end{array}$ & $\begin{array}{l}\text { Pengaruh pembe- } \\
\text { rian teknik aku- } \\
\text { presur terhadap } \\
\text { nyeri persalinan } \\
\text { kala I fase aktif di } \\
\text { RSUD Ambarawa }\end{array}$ & 22 & $\begin{array}{l}\text { Pre- } \\
\text { eksperi- } \\
\text { mental }\end{array}$ & $\begin{array}{l}\text { Sebelum diberikan akupresur ialah } 6,64 \text {. Hal ini } \\
\text { menunjukkan ibu bersalin rata-rata mengalami } \\
\text { nyeri sedang. Skala nyeri yang dirasakan paling } \\
\text { ringan adalah } 5 \text { dan yang paling berat ialah } 8 \text {. } \\
\text { sesudah diberikan akupresur adalah } 4,64 \text {. Hal ini } \\
\text { menunjukkan ibu bersalin rata-rata mengalami } \\
\text { nyeri sedang. Skala nyeri yang dirasakan paling } \\
\text { ringan adalah } 2 \text { dan yang paling berat adalah } 6 \text {. }\end{array}$ \\
\hline 6 & $\begin{array}{l}\text { Pangga- } \\
\text { yuh, } \\
\text { Kuswi- } \\
\text { yati, } \\
2019 .{ }^{16}\end{array}$ & $\begin{array}{l}\text { Lama kala I fase } \\
\text { aktif pada perla- } \\
\text { kuan TENS }\end{array}$ & 16 & $\begin{array}{l}\text { Pre- } \\
\text { eksperi- } \\
\text { mental }\end{array}$ & $\begin{array}{l}\text { Sebelum diberi perlakuan TENS, hampir sepa- } \\
\text { ruh responden }(31,25 \%) \text { mengalami nyeri } \\
\text { sedang, separuh responden }(50 \%) \text { mengalami } \\
\text { nyeri berat terkontrol, dan sebagian kecil res- } \\
\text { ponden }(18,75 \%) \text { mengalami nyeri berat tidak } \\
\text { terkontrol. Setelah diberi perlakuan TENS, } \\
\text { sebagian kecil responden }(12,5 \%) \text { mengalami } \\
\text { nyeri sangat ringan, separuh responden }(50 \%) \\
\text { mengalami nyeri sedang dan hampir setengah } \\
\text { responden (37,5\%) mengalami nyeri berat } \\
\text { terkontrol. }\end{array}$ \\
\hline 7 & $\begin{array}{l}\text { Yuliya- } \\
\text { nik, } \\
\text { Patemah, } \\
2014 .^{17}\end{array}$ & $\begin{array}{l}\text { Implementasi } \\
\text { metode transcuta- } \\
\text { neous electrical } \\
\text { nerve stimulation } \\
\text { (TENS) untuk } \\
\text { mengatasi nyeri } \\
\text { persalinan kala } 1 \\
\text { fase aktif pada ibu } \\
\text { bersalin }\end{array}$ & 25 & $\begin{array}{l}\text { Pre- } \\
\text { eksperi- } \\
\text { mental }\end{array}$ & $\begin{array}{l}\text { Sebelum perlakuan TENS terdapat } 22 \text { respon- } \\
\text { den }(88 \%) \text { yang mengalami nyeri sedang dan } 3 \\
\text { responden }(12 \%) \text { yang mengalami nyeri berat. } \\
\text { Setelah diberikan perlakuan TENS } 23 \text { respon- } \\
\text { den }(92 \%) \text { mengalami nyeri ringan dan } 2 \\
\text { responden ( } 8 \% \text { ) mengalami nyeri sedang. }\end{array}$ \\
\hline 8 & $\begin{array}{l}\text { Karlinah, } \\
\text { Irianti. } \\
2020 .^{10}\end{array}$ & $\begin{array}{l}\text { Effect of } \\
\text { transcutaneous } \\
\text { electrical nerve } \\
\text { stimulation (TENS) } \\
\text { on the pain intensity } \\
\text { phase i stage of } \\
\text { labor active. }\end{array}$ & 40 & $\begin{array}{l}\text { Eksperi- } \\
\text { mental }\end{array}$ & $\begin{array}{l}\text { Tidak ada perbedaan antara kelompok intervensi } \\
\text { dan kontrol TENS pada dilatasi serviks } 4 \mathrm{~cm} \text {. } \\
\text { Sedangkan hasil analisis pengaruh kelompok } \\
\text { TENS terhadap intensitas nyeri pada bukaan } \\
\text { serviks } 8 \mathrm{~cm} \text {, menunjukkan bahwa terdapat } \\
\text { perbedaan antara kelompok intervensi dan } \\
\text { kelompok kontrol, }\end{array}$ \\
\hline 9 & $\begin{array}{l}\text { Amalia, } \\
\text { Jayanti, } \\
2015 .^{18}\end{array}$ & $\begin{array}{l}\text { Pengeluaran } \\
\text { hormon endorphin } \\
\text { alami dengan me- } \\
\text { tode transcuta- } \\
\text { neous electrical } \\
\text { nerve stimulation } \\
\text { (TENS) untuk me- } \\
\text { ngendalikan } \\
\text { intensitas after } \\
\text { pain pada ibu nifas }\end{array}$ & 20 & $\begin{array}{l}\text { Eksperi- } \\
\text { mental }\end{array}$ & $\begin{array}{l}\text { Sebelum dilakukan perlakuan dengan metode } \\
\text { TENS Dari } 20 \text { responden, terdapat } 18 \text { responden } \\
(80 \%) \text { yang mengalami nyeri sedang dan } 2 \\
\text { responden }(10 \%) \text { yang mengalami nyeri berat. } \\
\text { setelah diberikan perlakuan dengan metode } \\
\text { TENS. Dari } 20 \text { responden, } 18 \text { responden }(90 \%) \\
\text { mengalami nyeri ringan dan } 2 \text { responden }(10 \%) \\
\text { mengalami nyeri sedang. }\end{array}$ \\
\hline
\end{tabular}




\begin{tabular}{|c|c|c|c|c|c|}
\hline 10 & $\begin{array}{l}\text { Baker, } \\
\text { Rashad, } \\
2016 .{ }^{19}\end{array}$ & $\begin{array}{l}\text { Effect of trans- } \\
\text { cutaneous elec- } \\
\text { trical nerve stimu- } \\
\text { lation (TENS) on } \\
\text { pain intensity } \\
\text { among multipara } \\
\text { women during the } \\
\text { first stage of labor }\end{array}$ & 40 & $\begin{array}{l}\text { Eksperi- } \\
\text { mental }\end{array}$ & $\begin{array}{l}\text { Perbedaan yang sangat signifikan secara } \\
\text { statistik terlihat antara kelompok eksperimen } \\
\text { dan kelompok kontrol setelah } 60 \text { dan } 90 \text { menit } \\
\text { intervensi mengenai keparahan nyeri persalinan }\end{array}$ \\
\hline
\end{tabular}

Tabel 2. Distribusi hasil uji statistik masing-masing literature penelitian

\begin{tabular}{clll}
\hline No & \multicolumn{1}{c}{ Peneliti } & \multicolumn{1}{c}{ Uji Statistik } & \multicolumn{1}{c}{ Nilai p } \\
\hline 1 & Vitriani et al $^{11}$ & T-test dependent & $\mathrm{p}=0,000$ (bermakna) \\
2 & ${\text { Dewiani et } \text { al }^{12}}^{12}$ & Mann Whitney & $\mathrm{p}=0,04$ (bermakna) \\
3 & Sulistyoningrum $^{13}$ & T-test dependent & $\mathrm{p}=0,000$ (bermakna) \\
4 & Puspadewi, Lokawati $^{14}$ & Wilcoxon & $\mathrm{p}=<0,05$ (Bermakna) \\
5 & Nanur $^{15}$ & Wilcoxon & $\mathrm{p}=0,0001$ (bermakna) \\
6 & Panggayuh, Kuswiyati $^{16}$ & Semua uji statistik dilakukan & $\mathrm{p}=0,01$ (bermakna) \\
7 & Yuliyanik, Patemah $^{17}$ & Wilcoxon & $\mathrm{p}=0,001$ (bermakna) \\
8 & Karlinah, Irianti $^{10}$ & chi-square & $\mathrm{p}=<0,05$ (bermakna) \\
& & & $\mathrm{p}=>0,05$ (tidak bermakna) \\
9 & Amalia, Jayanti $^{18}$ & Wilcoxon & $\mathrm{p}=0,000$ (Bermakna) \\
10 & Baker, Rashad $^{19}$ & Semua uji statistik dilakukan & $\mathrm{p}=0,0001$ (Bermakna) \\
\hline
\end{tabular}

\section{BAHASAN}

Berdasarkan literatur yang dikaji didapatkan karakteristik intensitas nyeri persalinan kala I fase aktif sebelum diberikan terapi akupresur yaitu sebagian besar responden (42 orang; 50,6\%) mengalami nyeri berat, hampir setengah dari responden $(35$ orang; 42,1\%) mengalami nyeri sedang, sedangkan sebagian kecil responden (masingmasing 3 orang; 3,6\%) mengalami nyeri ringan dan nyeri sangat berat. Setelah diberikan terapi akupresur, karakteristik intensitas nyeri pada persalinan menjadi $45,7 \%$ mengalami nyeri ringan, $31,3 \%$ mengalami nyeri sedang, 22,8\% mengalami nyeri berat dan tidak ada lagi dengan nyeri yang sangat berat. Dengan demikian dapat disimpulkan bahwa terdapat perubahan bermakna setelah pemberian terapi akupresur pada ibu bersalin kala I fase aktif. ${ }^{11-15}$

Selain akupresur, tindakan yang juga sering dilakukan dalam manajemen nyeri persalinan ialah TENS. Pemberian terapi TENS dapat meningkatkan rasa nyaman yang mungkin diakibatkan oleh peningkatan kadar endorfin yang dapat menurunkan sensitifitas nyeri dan memberi rasa tenang. Karakteristik intensitas nyeri persalinan kala I fase aktif sebelum dilakukan tindakan TENS dapat diinterpretasikan bahwa sebagian besar (45 orang; $73,7 \%$ ) mengalami nyeri sedang dan sisanya (16 orang; $26,2 \%$ ) mengalami nyeri berat, Setelah diberikan terapi TENS, karakteristik intensitas nyeri persalinan kala I fase aktif berubah menjadi sebagian besar $(70,4 \%)$ mengalami nyeri ringan, sebagian responden $(19,6 \%)$ mengalami nyeri sedang, dan sebagian kecil $(9,8 \%)$ mengalami nyeri berat. Dari lima literatur yang dikaji, empat literatur memiliki hasil yang sama yaitu terjadi perubahan nyeri yang bermakna setelah pemberian terapi TENS. Namun terdapat satu literatur (penelitian dari Karlinah dan Irianti ${ }^{10}$ ) yang melaporkan bahwa pada pembukaan serviks $8 \mathrm{~cm}$ tidak ditemukan perubahan bermakna setelah pemberian terapi TENS namun pada pembukaan serviks $4 \mathrm{~cm}$ terdapat perubahan bermakna setelah pemberian TENS. ${ }^{16-20}$ 


\section{SIMPULAN}

Akupresur dan TENS dapat menurunkan intensitas nyeri persalinan pervaginam secara bermakna. Disarankan bagi peneliti lanjut untuk mengembangkan metode terapi akupresur dan TENS pada berbagai kondisi lainnya yang disertai nyeri agar dapat mengurangi efek samping obat-obatan.

\section{Konflik Kepentingan}

Penulis menyatakan tidak terdapat konflik kepentingan dalam studi ini.

\section{DAFTAR PUSTAKA}

1. Bahrudin M. Patofisiologi nyeri (pain). Saintika Med. 2018;13(1):7. Doi:10. 22219/sm. v13i1.5449

2. Charles E. Argoff CE, Dubin A, Pilitsis J. Pain Management Secrets (4th ed). Elsevier, 2018; p. 45-6.

3. Pratiwi IG, Riska H, Kristinawati K. Manajemen mengurangi kecemasan dan nyeri dalam persalinan dengan menggunakan virtual reality: a review. Jurnal Kebidanan (JKB). 2019;9(1):17-21.

4. Syalfina AD. Faktor risiko dan penanganan nyeri persalinan. Hosp Majapahit. 2017; 9(2):78-88.

5. Moekroni R, Analia. Pengaruh pemberian terapi musik klasik dalam menurunkan tingkat kecemasan ibu hamil menjelang persalinan. Majority. 2016;5(1):6-11.

6. Rejeki S, Soejonoes A, Soenarjo AH. Tingkat nyeri dan prostaglandin-E2 pada ibu inpartu kala I dengan tindakan counterpressure. Jurnal Ners. 2014;9:111-7.

7. Maryuni. Hubungan karakteristik ibu bersalin dengan nyeri persalinan. Journal of Health Science and Physiotherapy. 2020;2(1): 116-122.

8. Rejeki S. Gambaran kadar PG-E 2 dan kadar interleukin-6 saat nyeri persalinan melalui metode counter pressure pada ibu dalam proses persalinan kala I. Prosiding Konferensi Nasional II PPNI Jawa Tengah 2014; p. 6-13.

9. Anita A. Pengaruh akupresur Lo4 (he kuk) dan Thai Cong terhadap tingkat nyeri persalinan kala I pada ibu bersalin. J Kesehat. 2018;9(3):471. Doi:10.26630/jk.v9i3.1166

10. Karlinah N, Irianti B. Effect of transcutaneous electrical nerve stimulation (TENS) on the pain intensity phase I stage of labor active in Bidan Praktik Mandiri Rahmadina Rosa 2019. J Midwifery Nurs. 2020;2(2):246-50.

11. Vitriani O, Lailiyana, Kasmenita. Pengaruh terapi akupresur terhadap intensitas nyeri persalinan pada ibu bersalin kala I di Puskesmas Sedinginan Tahun 2017. J Ibu dan Anak. 2018;6(1):1-9.

12. Dewiani K, Sardaniah, Pansori H. Therapi akupresur terhadap mengurangi rasa nyeri dan lama persalinan kala I pada primipara. Jurnal Kesehatan Poltekkes Provinsi Bengkulu. 2014;2(3):394-401.

13. Sulistyoningrum I. Pengaruh teknik akupresur terhadap pengurangan intensitas nyeri kala I persalinan. Tunas-tunas Ris Kesehat. 2017;6(2):5-9.

14. Puspadewi YA, Lokawati D. Pengaruh akupresur dalam mengurangi nyeri persalinan kala 1 fase aktif pada primigravida di BPM Ngadilah Kecamatan Pakis Malang. J Ilm Kesehat Media Husada. 2015;4(1):25-9. Doi:10.33475/jikmh. v4i1.164

15. Nanur FN, Masruroh. Pengaruh Pemberian teknik akupresur terhadap nyeri persalinan kala I fase aktif di RSUD Ambarawa 2013. Pros Semin Nas. 2014;(1):90-96.

16. Panggayuh A, Kuswiyati A. Lama kala I fase aktif pada perlakuan transcutaneous electrical nerve stimulation (TENS). MIKIA Mimb Ilm Kesehat Ibu dan Anak (Maternal Neonatal Heal Journal). 2019; 3(1):8-16. Doi:10.36696/mikia.v3i1.56.

17. Yuliyanik Y, Patemah P. Implementasi metode transcutaneous electrical nerve stimulation (Tens) untuk mengatasi nyeri persalinan kala I fase aktif pada ibu bersalin. J Ilm Kesehat Media Husada. 2014;2(2):55-60. Doi:10.33475/jikmh. v2i2.117

18. Amalia W, Jayanti ND. Pengeluaran hormon endorphine alami dengan metode transcutaneous electrical nerve stimulation (Tens) untuk mengendalikan intensitas afterpain pada ibu nifas. J Ilm Kesehat Media Husada. 2015;3(2):105-10. Doi:10.33475/jikmh.v3i2.157

19. Baker RMA, Rashad WAE. Effect of transcutaneous electrical nerve stimulation (TENS) on pain intensity among multipara women during the first stage of labor. Brain. 2016;4(8):79-90. Available from: https://pdfs.semanticscholar.org/c507/ b0db68c1f3781c0de69474cb4962d541ad 8d.pdf 
20. Nuraeni N, Kurniawati A, Gundara G. The effectiveness of Tens in reducing the pain levels amongst women in the first stage of give birth. J Matern Care Reprod Heal. 2018;1(2):428-36.

Doi:10.36780/jmcrh.v1i2.43 